\title{
Preparation of Three Types of Transformer Oil-Based Nanofluids and Comparative Study on the Effect of Nanoparticle Concentrations on Insulating Property of Transformer Oil
}

\author{
Qi Wang, ${ }^{1}$ Muhammad Rafiq, ${ }^{1}$ Yuzhen Lv, ${ }^{2}$ Chengrong Li, ${ }^{1}$ and Kai Yi ${ }^{2}$ \\ ${ }^{1}$ Beijing Key Laboratory of High Voltage \& EMC, North China Electric Power University, Beijing, China \\ ${ }^{2}$ School of Energy, Power and Mechanical Engineering, North China Electric Power University, Beijing, China \\ Correspondence should be addressed to Muhammad Rafiq; jutt96@gmail.com
}

Received 21 August 2015; Revised 26 November 2015; Accepted 30 November 2015

Academic Editor: Jorge M. Seminario

Copyright (C) 2016 Qi Wang et al. This is an open access article distributed under the Creative Commons Attribution License, which permits unrestricted use, distribution, and reproduction in any medium, provided the original work is properly cited.

\begin{abstract}
Nanofluids have the potential to become the alternatives of conventional transformer oil for their exquisite electrical and thermal properties. Three kinds of nanoparticles with distinct conductivities, namely, nonconductive nanoparticle $\mathrm{Al}_{2} \mathrm{O}_{3}$, conductive nanoparticle $\mathrm{Fe}_{3} \mathrm{O}_{4}$, and semiconductive nanoparticle $\mathrm{TiO}_{2}$, with different concentrations from $5 \%$ to $40 \%$ w/v were selected and suspended into transformer oil to develop nanofluids. The lightening impulse breakdown strengths of the oil samples with and without nanoparticles were measured according to IEC standard methods. The positive impulse breakdown strength indicated that breakdown strength is first increased up to the maximum value at certain concentration and then starts decreasing. The results of negative impulse breakdown manifested that the breakdown voltages of nanofluids with different concentrations were less than the breakdown voltage of pure transformer oil. Different effect mechanisms of dielectric and conductive nanoparticles were also used to describe the difference among three prepared nanofluids.
\end{abstract}

\section{Introduction}

The transformer is the most significant and essential part in the modern power grid system for transmission and distribution of electric power. Without it, the power grid simply would not be able to scale up to meet the growing demand of electricity. It is very important in ensuring reliability and safety of electric power system. The collapse of this vital part can be ruinous [1]. Most of transformers recently in service in many countries are approaching or beyond their designed life. Therefore there has been rising focus on enhancing the operational reliability of these existing units. The transformer failure data manifested that the average service life of transformers that collapsed due to dielectric insulation problems is 17.8 years, which is far less than the expected life of 35 to 40 years and $75 \%$ of high voltage transformer failures are caused by insulation problems $[2,3]$. Both the lifetime and operational reliability of transformers primarily depend on the status of oil-paper insulation system [4-6]. The insulating fluid in transformers is primarily used for cooling and insulation. However, highly refined mineral oil used in transformers has low thermal conductivity and thus has depressed cooling performance [1].

In recent years, a lot of research work has been carried out on nanodielectrics after the recent evolution in nanotechnology [7]. The result analysis has manifested that the suspension of nanoparticles can dramatically prolong the insulation life of solid polymers. This technique has been normally used for the outdoor insulation of power system [8]. However, for internal insulating liquid, most of the studies mainly focused on thermal characteristics [9-11].

The broad application of mineral oil for high voltage insulation and power apparatus cooling has prompted vast research work proposed to improve both of its dielectric and cooling characteristics through nanotechnology after significant research progress in nanodielectrics. A contemporary instance of this research work is the preparation of dielectric nanofluids. A fluid with dispersion of nanoparticles is named as nanofluid, a term conferred by Choi at Argonne National Lab in 1995 [12]. 
The transformer oil modified by conductive nanoparticles suspension has been studied by different researchers and the results showed excellent insulating and thermal characteristics which is highly desirable for the electric power system $[4,13,14]$. In 1990s, researchers found that transformer oil modified by conductive nanoparticles $\mathrm{Fe}_{3} \mathrm{O}_{4}$ has highly improved breakdown strength $[15,16]$. Later on, some researchers also identified that nonconductive nanoparticles such as $\mathrm{Al}_{2} \mathrm{O}_{3}$ and $\mathrm{TiO}_{2}$ can also help to improve insulation strength of transformer oil [17-20]. It was seen that both the contrary characteristics (conductivity or dielectric property) are contributory to the enhancement of breakdown performance of transformer oil. However, the development of nanofluids is still confronting a lot of challenges such as lack of agreement between results, inadequacy of theoretical understanding of the mechanism, and poor characterization of suspensions [21].

Comparative and systematic research studies on different transformer oil-based nanofluids with different concentration of nanoparticles have not been conducted, which is very significant for the optimization of huge transformers. The effects of different types of nanoparticle concentration on the breakdown properties of transformer oil under lightening impulse voltage need to be elaborated to compare the insulation properties of different transformer oil-based nanofluids with different concentrations. The improved breakdown voltages mechanism is closely related to the relaxation time constant and polarization of nanoparticles in nanofluids, which depends on the permittivity and conductivity of nanoparticles. Thus three different nanoparticles, that is, conductive magnetic nanoparticles $\mathrm{Fe}_{3} \mathrm{O}_{4}$, insulative nanoparticles $\mathrm{Al}_{2} \mathrm{O}_{3}$, and semiconductive nanoparticles $\mathrm{TiO}_{2}$, were used to develop nanofluids with different concentrations. This work aims to study comparatively the breakdown properties of prepared samples with different concentrations under lightening impulse stress with different polarities. The impulse breakdown strength was measured to analyze the influence of nanoparticle concentrations on the breakdown strength of transformer oil and to see the optimal concentration at which there is maximum enhancement in breakdown voltages. The mechanism of improved breakdown performance was also studied.

\section{Materials and Methods}

2.1. Test Material Selection. The Kelamayi mineral oil and nanoparticles with average size of $d<50 \mathrm{~nm}$ (which were purchased from a reputable Chinese company) were used in the tests. The mineral oil (25\#Kelamayi) was filtered to eliminate the impurities and to meet the demands of clean oil by CIGRE working group 12.17 [22]. In this test, the same specific concentrations of three nanofluids, namely, $5 \%, 10 \%$, $20 \%$, and $40 \%$, were selected. The basic properties of the three types of selected nanoparticles are also summarized in Table 1.

2.2. Preparation of Nanofluids. A certain amount of the selected nanoparticles $\mathrm{Al}_{2} \mathrm{O}_{3}, \mathrm{Fe}_{3} \mathrm{O}_{4}$, and $\mathrm{TiO}_{2}$ was weighed according to the desired concentration. The nanofluids were prepared by dispersing nanoparticles into transformer oil by the application of ultrasonic route. All the prepared samples with different concentrations were put into vacuum drying oven at less than $\mathrm{kPa}$ for almost $24 \mathrm{hrs}$ to dismiss the effect of microbubbles formed during the sonication process.

2.3. Breakdown Voltage Tests. The impulse breakdown voltage is simulating lightening strikes and normally uses a 1.2microsecond rise for the wave to attain $90 \%$ amplitude and then drops down to $50 \%$ amplitude after 50 microseconds. This test was conducted to measure the liquid's breakdown voltage under standard lightening impulse $(1.2 \mu \mathrm{s} / 50 \mu \mathrm{s})$. The standard lightening impulse was generated by a 10-stage impulse generator. A needle to sphere electrode geometry with adjustable gap distance was used for these tests. A gap distance of $25 \mathrm{~mm}$ was used for positive and $15 \mathrm{~mm}$ for negative impulse breakdown voltages according to IEC 60897 standard. The impulse breakdown voltages of pure oil and the prepared nanofluids were measured by using the oil tank and the electrode configuration shown in Figure 1. The oil tank and electrodes were soaked with the same fluid. The oil tank was filled with the sample in order to make sure that there were no gas bubbles. The needle electrode was changed after every breakdown to ensure same experimental conditions. Six breakdown values were gained for every sample to confirm repeatability. The average value was taken as lightening impulse breakdown voltage.

\section{Test Results and Analysis}

3.1. Positive Impulse Breakdown Strength. Positive impulse breakdown tests were carried out for both mineral oil and prepared nanofluids with different concentrations of nanoparticles. The results are shown in Figure 2. When nanoparticle's concentration is zero, it means that the fluid used for experiment is base transformer oil. It is clear from the figure that when the concentration is increased for $\mathrm{Al}_{2} \mathrm{O}_{3}$, the breakdown voltages increase until the maximum value at $20 \%$ concentration which is the optimum concentration for this nanofluid. The nanofluid modified by nonconductive nanoparticle $\mathrm{Al}_{2} \mathrm{O}_{3}$ showed the highest average positive impulse breakdown voltage of almost $86 \mathrm{kV}$ at $20 \%$ concentration, which is $13 \%$ higher than the average positive lightening impulse voltage of pure oil. The nanofluid modified by conductive nanoparticle $\mathrm{Fe}_{3} \mathrm{O}_{4}$ and semiconductive nanoparticles $\mathrm{TiO}_{2}$ showed the highest average positive impulse breakdown voltage of almost $82 \mathrm{kV}$ and $79 \mathrm{kV}$, respectively, at $10 \%$ concentration, so $10 \%$ is the optimal concentration for these nanofluids. Table 2 also shows that the average time to breakdown of nanofluids is longer than the corresponding values for pure oil. That is, it needs more time for the streamer to travel through the electrode gap to cause breakdown. The average streamer velocity $v$ is defined as the ratio of the electrode gap $(d)$ and time to breakdown $(t)$ :

$$
v=\frac{d}{t} .
$$


TABLE 1: Basic properties of chosen nanoparticles.

\begin{tabular}{lcccc}
\hline Properties & Transformer oil & $\mathrm{Fe}_{3} \mathrm{O}_{4}$ & $\mathrm{Al}_{2} \mathrm{O}_{3}$ & $\mathrm{TiO}_{2}$ \\
\hline Relative permittivity [16, 31] & 2.2 & 80 & 9.9 & 114 \\
Conductivity (S/m) $[16,31]$ & $10^{-12}$ & $10^{4}-10^{5}$ & $10^{-12}$ & $10^{-11}$ \\
Density $\left(\mathrm{g} / \mathrm{cm}^{3}\right)$ & 0.89 & 5.18 & 3.97 & $4.2-4.3$ \\
Relaxation time (s) & - & $7.47 \times 10^{-14}$ & 42.2 & 77 \\
Surface modification & - & - & - & - \\
Material type & Dielectric & Conductor & Insulator & Semiconductor \\
\hline
\end{tabular}

TABLE 2: Breakdown results of pure oil and different types of nanofluids under positive lightening impulse voltage.

\begin{tabular}{|c|c|c|c|c|c|c|}
\hline \multirow{2}{*}{$\begin{array}{l}\text { Nanoparticles } \\
\text { concentration } \\
(\% \mathrm{w} / \mathrm{v})\end{array}$} & \multicolumn{2}{|c|}{$\mathrm{Fe}_{3} \mathrm{O}_{4}$} & \multicolumn{2}{|c|}{$\mathrm{TiO}_{2}$} & \multicolumn{2}{|c|}{$\mathrm{Al}_{2} \mathrm{O}_{3}$} \\
\hline & $\begin{array}{c}\text { Time to } \\
\text { breakdown }(\mu \mathrm{s})\end{array}$ & $\begin{array}{c}\text { Average } \\
\text { streamer } \\
\text { velocity }(\mathrm{km} / \mathrm{s})\end{array}$ & $\begin{array}{c}\text { Time to } \\
\text { breakdown }(\mu \mathrm{s})\end{array}$ & $\begin{array}{c}\text { Average } \\
\text { streamer } \\
\text { velocity }(\mathrm{km} / \mathrm{s})\end{array}$ & $\begin{array}{l}\text { Time to } \\
\text { breakdown }(\mu \mathrm{s})\end{array}$ & $\begin{array}{c}\text { Average } \\
\text { streamer } \\
\text { velocity }(\mathrm{km} / \mathrm{s})\end{array}$ \\
\hline 0 & 13.03 & 1.91 & 13.03 & 1.91 & 13.03 & 1.91 \\
\hline 5 & 14.12 & 1.77 & 13.94 & 1.79 & 14.23 & 1.75 \\
\hline 10 & 14.63 & 1.70 & 14.06 & 1.77 & 14.77 & 1.69 \\
\hline 20 & 13.67 & 1.82 & 13.07 & 1.91 & 15.62 & 1.60 \\
\hline 40 & 13.20 & 1.89 & 12.90 & 1.93 & 14.51 & 1.72 \\
\hline
\end{tabular}

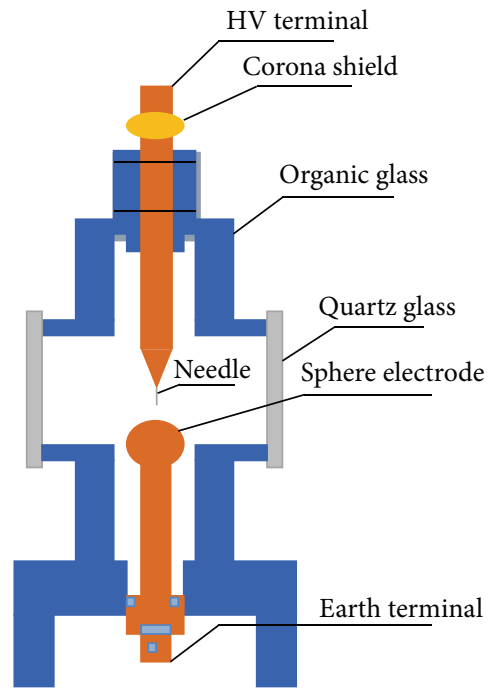

FIGURE 1: Test cell for impulse breakdown measurement.

The time to breakdown and streamer velocity for pure oil and nanofluids with different concentration under positive lighting impulse breakdown voltages are shown in Table 2 .

3.2. Negative Impulse Breakdown Strength. Negative impulse breakdown tests were carried out for both mineral oil and prepared nanofluids with different concentrations of nanoparticles. The results of three types of nanofluids with different nanoparticles concentration are shown in Figure 3. They indicate that the breakdown voltage decreases for all types of nanofluids with the increase of nanoparticles concentration and are always smaller than the base pure oil, which is inconsistent with the observation of others [15].

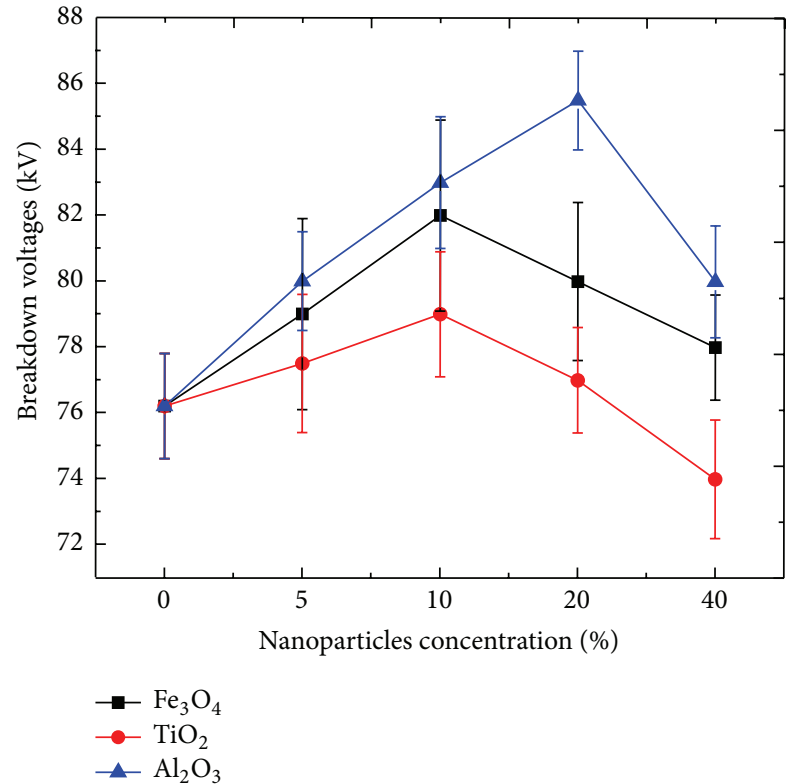

FIGURE 2: Positive impulse breakdown voltages of different nanofluids with different concentrations (25 mm gap distance).

The time to breakdown and streamer velocity under negative impulse breakdown voltage are shown in Table 3.

\section{Discussion and Mechanism Analysis}

Although the basic properties like conductivities and permittivity of three types of nanoparticles are different, the suspension of different nanoparticles with different concentrations improves the insulation performance of transformer oil until certain loading of nanoparticles. 
TABLE 3: Breakdown results of pure oil and different types of nanofluids under negative lightening impulse voltage.

\begin{tabular}{|c|c|c|c|c|c|c|}
\hline \multirow[b]{2}{*}{$\begin{array}{l}\text { Nanoparticles } \\
\text { concentration } \\
(\% \mathrm{w} / \mathrm{v})\end{array}$} & \multicolumn{2}{|c|}{$\mathrm{Fe}_{3} \mathrm{O}_{4}$} & \multicolumn{2}{|c|}{$\mathrm{TiO}_{2}$} & \multicolumn{2}{|c|}{$\mathrm{Al}_{2} \mathrm{O}_{3}$} \\
\hline & $\begin{array}{c}\text { Time to } \\
\text { breakdown }(\mu \mathrm{s})\end{array}$ & $\begin{array}{c}\text { Average } \\
\text { streamer } \\
\text { velocity }(\mathrm{km} / \mathrm{s})\end{array}$ & $\begin{array}{c}\text { Time to } \\
\text { breakdown }(\mu \mathrm{s})\end{array}$ & $\begin{array}{c}\text { Average } \\
\text { streamer } \\
\text { velocity }(\mathrm{km} / \mathrm{s})\end{array}$ & $\begin{array}{c}\text { Time to } \\
\text { breakdown }(\mu \mathrm{s})\end{array}$ & $\begin{array}{c}\text { Average } \\
\text { streamer } \\
\text { velocity }(\mathrm{km} / \mathrm{s})\end{array}$ \\
\hline 0 & 23.70 & 0.63 & 23.70 & 0.63 & 23.70 & 0.63 \\
\hline 5 & 21.71 & 0.69 & 22.04 & 0.68 & 20.02 & 0.74 \\
\hline 10 & 19.98 & 0.75 & 21.05 & 0.71 & 18.26 & 0.82 \\
\hline 20 & 18.86 & 0.80 & 19.61 & 0.76 & 17.11 & 0.87 \\
\hline 40 & 16.70 & 0.90 & 18.03 & 0.83 & 15.80 & 0.95 \\
\hline
\end{tabular}

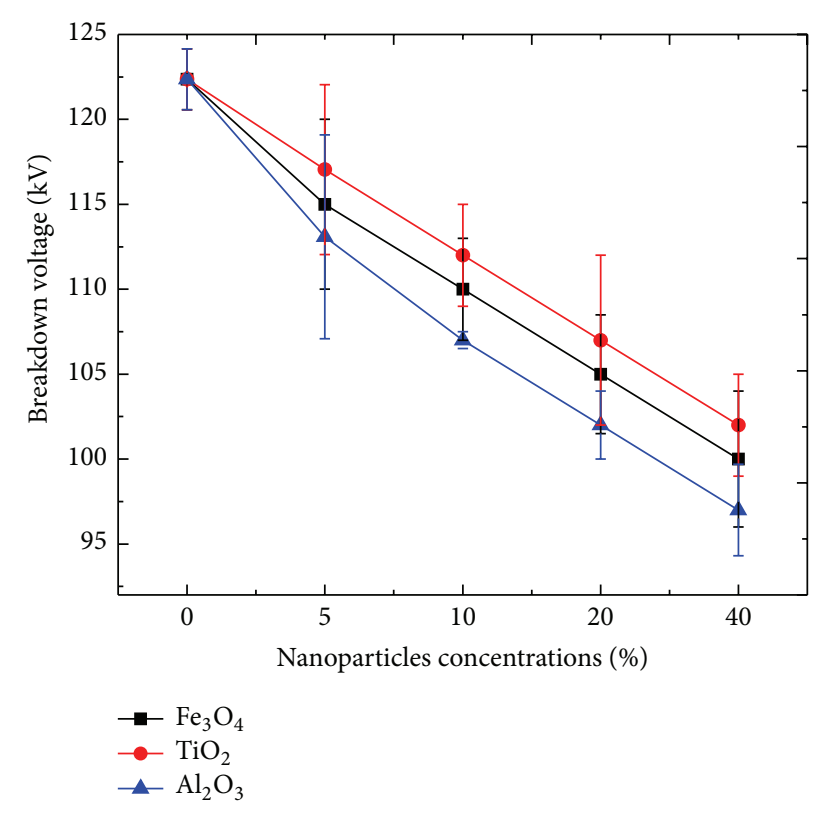

Figure 3: Negative impulse breakdown voltages of different nanofluids with different concentrations (15 mm gap distance).

The differences in the enhancement of breakdown strength among the nanofluids modified by different nanoparticles are also worth examining. The research work has showed that the space charge effect is a very vital factor that influences the initiation and development of streamer [23]. Many researchers believe that special interfacial characteristics between transformer oil and nanoparticles play a crucial role in space charge transportation during breakdown process in nanofluids [24-26]. The interface area consists of a lot of electronic traps that can trap and release electrons frequently. These trapping and detrapping processes decrease the velocity and energy transfer of electrons and impede the development of streamer.

4.1. Mechanisms of Improved Breakdown Strength. The suspension of nanoparticles in transformer oil alters the space charge distribution and, therefore, the breakdown properties of nanofluids and pure oil are quite different. When increasing positive impulse voltage is applied, a corona discharge happens near the positive needle electrode with highest local electric field strength. The molecules near the needle electrode are ionized in transformer oil. A huge amount of space charges is created by this field ionization. In pure oil, high mobility electrons are produced at high field and neutralized at positive needle electrode. A large amount of positive ions is accumulated near the needle electrode because of their low mobility. This newly formed spatial electric field weakens the external electric field near the needle electrode and strengthens the external field between positive ions and sphere electrode. The malposition of positive ions near the positive needle electrode results in superposition spatial electric field, which highly distorts the applied electric field. However, in case of nanofluids, the most of the high mobility electrons produced as a result of ionization are captured by nanoparticles and negative ions are formed. The slow mobile negative ions and negatively charged nanoparticles are left in the ionization zone. A superposition spatial electric filed is produced in ionization zone near the needle electrode due to malposition of positive and negative ions, which distorts the applied electric field. The presence of negatively charged nanoparticles near the needle electrode reduces the distortion effect which is higher in the case of pure oil. Therefore, it is more difficult to expand corona discharge outwards than the corona discharge in pure oil when voltages are continuously increased. The negatively charged nanoparticles move toward the needle electrode and positive charges move toward the sphere electrode.

By contrast, the situation with negative impulse voltages is different. The ionization of transformer oil happens near the negative needle electrode after space charge and corona generation [27]. When the negative impulse is applied to the nanofluids, a small portion of positive ions produced by field ionization are neutralized after reaching to the needle electrode. The remaining parts of positive ions are retained at negative needle electrode. A large number of negatively charged slow nanoparticles also remain near the negative electrode. This phenomenon weakens the electric field strength at needle electrode and strengthens at plate electrode. Therefore, enhancement of voltage is conducive to the initiation and development of streamer to the anode, thus decreasing the negative breakdown voltages with the suspension of nanoparticles [27]. It is well described that conventional transformer oil has higher impulse breakdown voltages value with negative impulse voltages application [28]. This difference between positive and negative impulse 
voltages has also been explained and confirmed by direct observation of breakdown events particularly difference in streamer formation mechanism [29]. The difference in streamer mechanism of streamer formation leads to its different geometry and results in the fact that the positive streamer propagates at a much higher speed than the negative streamer across the gap between the electrodes. Taking all these factors into account, different sets of data were obtained with different concentrations on the impulse breakdown of the colloidal fluid with negative polarity of the needle electrode.

4.2. Mechanism of Action of Different Nanoparticles. This paper provides an explanation to understand the differences in the breakdown properties of different types of nanofluids on the basis of relaxation theory and trap model. According to Hwang et al. [16] the relaxation time constant of the free charges trapped on the nanoparticles is less than the time scale required for the streamer propagation; the presence of nanoparticles will effectively modify the electrodynamics in the oil. The relaxation time constant can be defined by the following expression [16]:

$$
\tau_{r}=\frac{2 \varepsilon_{1}+\varepsilon_{2}}{2 \sigma_{1}+\sigma_{2}},
$$

where $\sigma_{1}$ and $\sigma_{2}$ are conductivities of transformer oil and nanoparticles, respectively, and $\varepsilon_{1}$ and $\varepsilon_{2}$ are the permittivities of transformer oil and nanoparticles, respectively. A small value of relaxation time constant means fast absorption of electrons on the surface of nanoparticles. The relaxation time constant for conductive nanoparticles $\mathrm{Fe}_{3} \mathrm{O}_{4}$ is less than the propagation time constant of the streamer. Therefore, the surface of the nanoparticles can capture free electrons rapidly, thus modifying the potential distribution around the nanoparticles [30].

On the other hand, the relaxation time constant of insulative nanoparticle $\mathrm{Al}_{2} \mathrm{O}_{3}$ and semiconductive nanoparticle $\mathrm{TiO}_{2}$ is larger than streamer propagation time. When these nanofluids are exposed to external electric field, the free charge will not have enough time to accumulate at the surface of nanoparticles. By contrast, the charges produced by polarization will change the surface potential distribution of the nanoparticles. Thus the polarization of dielectric nanoparticles $\left(\mathrm{TiO}_{2}\right.$ and $\left.\mathrm{Al}_{2} \mathrm{O}_{3}\right)$ is created by polarization charges instead of free charges [17]. These polarized nanoparticles will also produce potential wells that are required for trapping electrons.

The above explanation indicated that the polarization which changes the potential distribution along the surface of nanoparticles is primarily responsible for different breakdown properties among different nanofluids. Moreover the results of breakdown voltages for $\mathrm{Fe}_{3} \mathrm{O}_{4}$ nanofluids are different from the breakdown voltage of $\mathrm{Al}_{2} \mathrm{O}_{3}$ and $\mathrm{TiO}_{2}$ nanofluids. The results certify that how $\mathrm{Fe}_{3} \mathrm{O}_{4}$ nanoparticles behave to the applied electric field is different from the polarized charges on $\mathrm{Al}_{2} \mathrm{O}_{3}$ and $\mathrm{TiO}_{2}$ nanoparticles. Nevertheless, more research is required on the topic.
4.3. Breakdown Mechanism after Agglomeration. When the nanoparticles volume concentration is lower than a critical value after which the nanoparticles start to agglomerate, the added nanoparticles are responsible for delaying the molecular ionization and ultimately streamer initiation and development further into the fluid, and hence they improve the dielectric breakdown voltage of the liquid. However, when the nanoparticles volume concentration is higher than a critical value, the particles start to agglomerate and form chains near the electrodes, which give rise to the local electric field. And it ultimately leads to streamer initiation and development and finally breakdown occurs at a low voltage. That critical value in our results is $10 \%$ nanoparticle's concentration for $\mathrm{TiO}_{2}$ and $\mathrm{Fe}_{3} \mathrm{O}_{4}$ nanofluids and $20 \%$ for $\mathrm{Al}_{2} \mathrm{O}_{3}$ nanofluids for positive impulse breakdown voltages.

\section{Conclusions}

In this paper, three different types of nanoparticles were selected and transformer oil-based nanofluids were prepared with multiple nanoparticles volume concentration. The impulse breakdown strength of prepared nanofluids was tested and analyzed. The conclusions obtained from this study are as follows:

(i) The positive lightening impulse breakdown voltages of three nanofluids modified by $\mathrm{Al}_{2} \mathrm{O}_{3}, \mathrm{TiO}_{2}$, and $\mathrm{Fe}_{3} \mathrm{O}_{4}$ showed improvement as the concentration is increased until a critical value of concentration after which it starts decreasing. Due to the presence of these nanoparticles, higher breakdown corresponds to longer time to breakdown.

(ii) The variation in space charge distribution caused by suspension of nanoparticle manifested that the presence of negatively charged particles changes the space electric field distribution and decreases/increases the breakdown properties. The differences in the cause of polarization among dielectric nanoparticles and conductive nanoparticles result in different breakdown performance among different types of nanofluids.

(iii) The suspension of nanoparticles improves the breakdown performance of oil until a critical value of nanoparticle concentration after which the breakdown voltage tends to decrease. This decrease in breakdown voltages is mainly attributed to agglomeration of nanoparticles at higher volume concentration.

(iv) For negative impulse breakdown voltages, the transformer oil showed higher dielectric strength as compared to the nanofluids with different concentrations.

\section{Conflict of Interests}

The authors declare that there is no conflict of interests regarding the publication of this paper. 


\section{Authors' Contribution}

Qi Wang and Muhammad Rafiq contributed to the nanofluids preparation and experimental work equally.

\section{References}

[1] D. Peterchuck and A. Pahwa, "Sensitivity of transformer's hottest-spot and equivalent aging to selected parameters," IEEE Transactions on Power Delivery, vol. 17, no. 4, pp. 996-1001, 2002.

[2] W. H. Bartley, "Investigating transformer failure," in Proceedings of the 5th Weidmann-ACTI Annual Technical Conference on New Diagnostic Concepts for Better Asset Management, November 2006.

[3] EPRI Portfolio 2007-Transmission reliability and performance: 37.002, transformer life extension, http://www.epri .com/portfolio/.

[4] M. Chiesa and S. K. Das, "Experimental investigation of the dielectric and cooling performance of colloidal suspensions in insulating media," Colloids and Surfaces A: Physicochemical and Engineering Aspects, vol. 335, no. 1-3, pp. 88-97, 2009.

[5] T. O. Rouse, "Mineral insulating oil in transformers," IEEE Electrical Insulation Magazine, vol. 14, no. 3, pp. 6-16, 1998.

[6] L. E. Lundgaard, W. Hansen, D. Linhjell, and T. J. Painter, "Aging of oil-impregnated paper in power transformers," IEEE Transactions on Power Delivery, vol. 19, no. 1, pp. 230-239, 2004.

[7] Y. Cao, P. C. Irwin, and K. Younsi, "The future of nanodielectrics in the electrical power industry," IEEE Transactions on Dielectrics and Electrical Insulation, vol. 11, no. 5, pp. 797-807, 2004.

[8] M. Roy, J. K. Nelson, R. K. MacCrone et al., "Polymer nanocomposite dielectrics-the role of the interface," IEEE Transactions on Dielectrics and Electrical Insulation, vol. 12, no. 4, pp. 629642, 2005.

[9] V. E. Fertman, Magnetic Fluids Guidebook: Properties and Applications, Hemisphere Publishing, New York, NY, USA, 1990.

[10] B. M. Berkovski and V. Bashtovoy, Magnetic Fluids and Applications Handbook, Begall House, New York, NY, USA, 1996.

[11] Y. Cao, P. C. Irwin, and K. Younsi, "The future of nanodielectrics in the electrical power industry," IEEE Transactions on Dielectrics and Electrical Insulation, vol. 11, no. 5, pp. 797-807, 2004.

[12] S. Choi, "Enhancing thermal conductivity of fluids with nanoparticles," in Developments and Applications of NonNewtonian Flows, vol. 231 of ASME FED, pp. 99-105, 1995.

[13] E. C. Nsofor, "Recent patents on nanofluids (nanoparticles in liquids) heat transfer," Journal of Recent Patents on Mechanical Engineering, vol. 1, no. 3, pp. 190-197, 2008.

[14] L. E. Lundgaard, W. Hansen, D. Linhjell, and T. Painter, "Ageing of mineral oil impregnated cellulose by acid catalysis," IEEE Transactions on Dielectrics and Electrical Insulation, vol. 15, no. 2, pp. 540-546, 2008.

[15] V. Segal, A. Hjortsberg, A. Rabinovich, D. Nattrass, and K. Raj, "AC $(60 \mathrm{~Hz})$ and impulse breakdown strength of a colloidal fluid based on transformer oil and magnetite nanoparticles," in Proceedings of the Conference Record of the IEEE International Symposium in Electrical Insulation, pp. 619-622, Arlington, Va, USA, June 1998.

[16] J. G. Hwang, M. Zahn, F. M. O’Sullivan, L. A. A. Pettersson, O. Hjortstam, and R. S. Liu, "Effects of nanoparticle charging on streamer development in transformer oil-based nanofluids," Journal of Applied Physics, vol. 107, no. 1, Article ID 014310, 2010.

[17] T. Takada, Y. Hayase, Y. Tanaka, and T. Okamoto, "Space charge trapping in electrical potential well caused by permanent and induced dipoles for LDPE/MgO nanocomposite," IEEE Transactions on Dielectrics and Electrical Insulation, vol. 15, no. 1, pp. 152-160, 2008.

[18] Y. F. Du, Y. Z. Lv, C. R. Li et al., "Effect of semiconductive nanoparticles on insulating performances of transformer oil," IEEE Transactions on Dielectrics and Electrical Insulation, vol. 19, no. 3, pp. 770-776, 2012.

[19] Y. Du, Y. Lv, C. Li et al., "Effect of electron shallow trap on breakdown performance of transformer oil-based nanofluids," Journal of Applied Physics, vol. 110, no. 10, Article ID 104104, 2011.

[20] Y.-X. Zhou, Y.-S. Wang, J.-H. Tian et al., "Breakdown characteristics in transformer oil modified by nanoparticles," High Voltage Engineering, vol. 36, no. 5, pp. 1155-1159, 2010.

[21] X.-Q. Wang and A. S. Mujumdar, "Heat transfer characteristics of nanofluids: a review," International Journal of Thermal Sciences, vol. 46, no. 1, 2007.

[22] CIGRE, "The effect of particles on dielectric strength," working group of 17 committee, 12 June 2002.

[23] R. Bartinikas, Electrical Insulating Liquids, ASTM Publication, Philadelphia, Pa, USA, 1994.

[24] T. J. Lewis, "Interfaces: nanometric dielectrics," Journal of Physics D: Applied Physics, vol. 38, no. 2, pp. 202-212, 2005.

[25] R. C. Smith, C. Liang, M. Landry, J. K. Nelson, and L. S. Schadler, "The mechanisms leading to the useful electrical properties of polymer nanodielectrics," IEEE Transactions on Dielectrics and Electrical Insulation, vol. 15, no. 1, pp. 187-196, 2008.

[26] M. G. Danikas, "On two nanocomposite models: differences, similarities and interpretational possibilities regarding Tsagaropoulos' model and Tanaka's model," Journal of Electrical Engineering, vol. 61, no. 4, pp. 241-246, 2010.

[27] W.-X. Sima, X.-F. Cao, Q. Yang, H. Song, and J. Shi, "Preparation of three transformer oil-based nanofluids and comparison of their impulse breakdown characteristics," Nanoscience and Nanotechnology Letters, vol. 6, no. 3, pp. 250-256, 2014.

[28] Yu. V. Torshin, "On the existence of leader discharges in mineral oil," IEEE Transactions on Dielectrics and Electrical Insulation, vol. 2, no. 1, pp. 167-178, 1995.

[29] E. O. Foster, Electrical Insulating Liquids, edited by: Bartnikas, ASTM International, Philadelphia, Pa, USA, 1994.

[30] J. Li, Z. T. Zhang, P. Zou, S. Grzybowski, and M. Zahn, "Preparation and experimental investigation of breakdown and dielectric properties of vegetable-oil-based nanofluid," IEEE Electrical Insulation Magazine, vol. 28, no. 5, pp. 43-50, 2012.

[31] Y.-F. Du, Y.-Z. Lv, F.-C. Wang, X.-X. Li, and C.-R. Li, "Effect of $\mathrm{TiO}_{2}$ nanoparticles on the breakdown strength of transformer oil," in Proceedings of the IEEE International Symposium on Electrical Insulation (ISEI '10), pp. 1-3, IEEE, San Diego, Calif, USA, June 2010. 

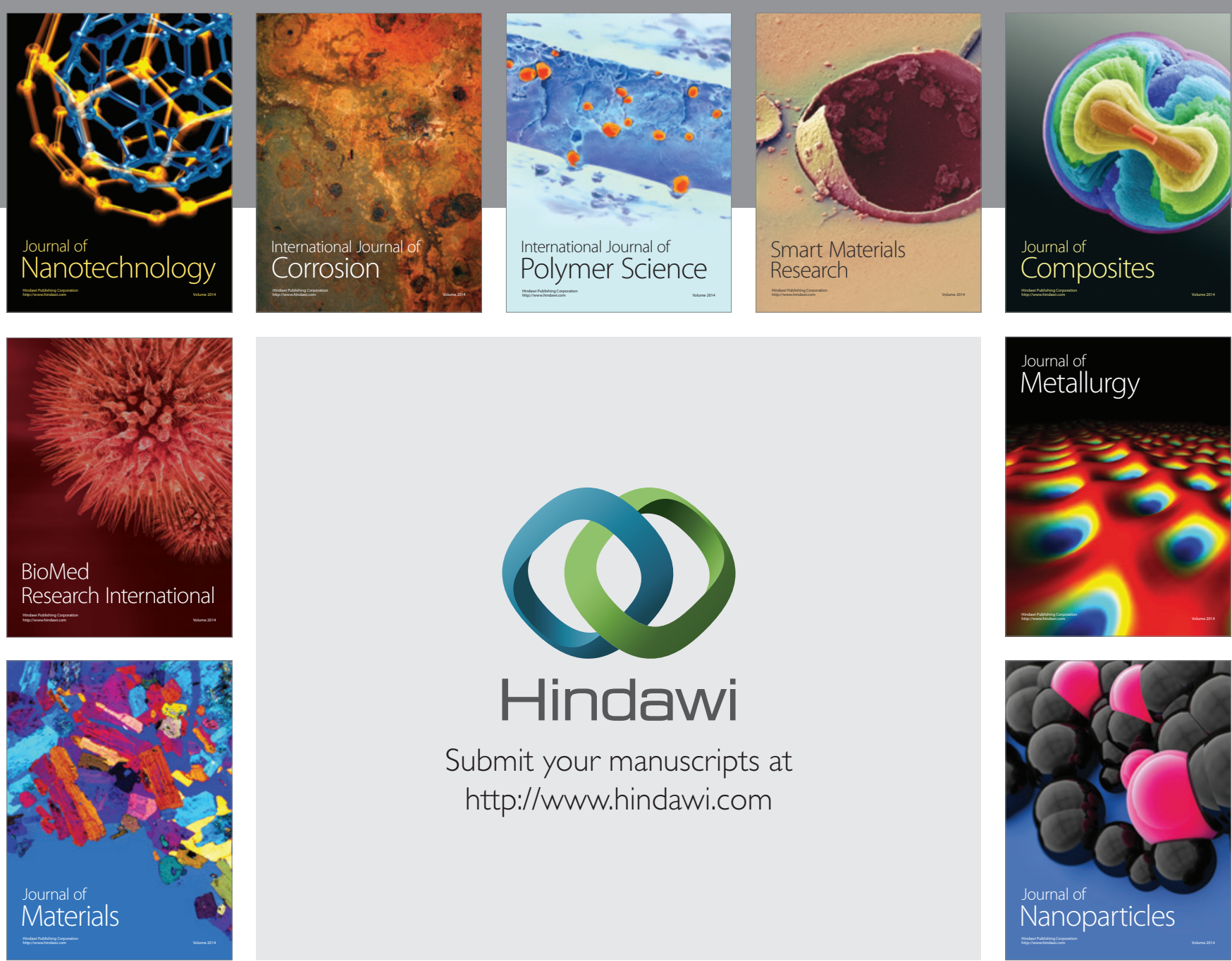

\section{Hindawi}

Submit your manuscripts at

http://www.hindawi.com

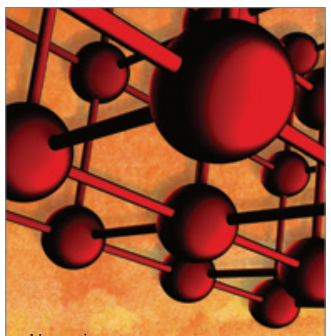

Materials Science and Engineering
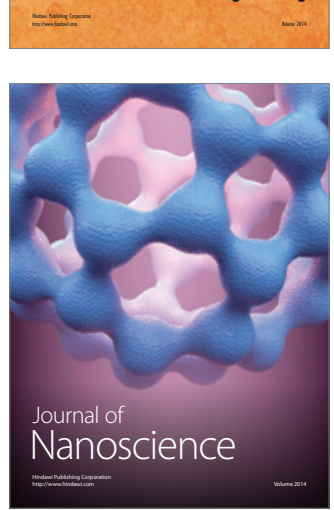
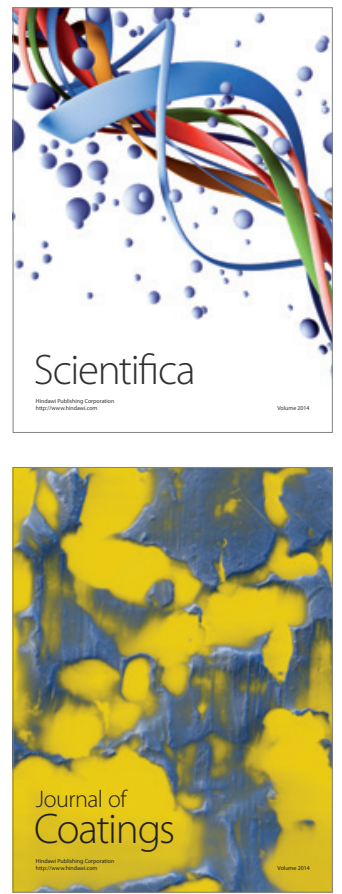
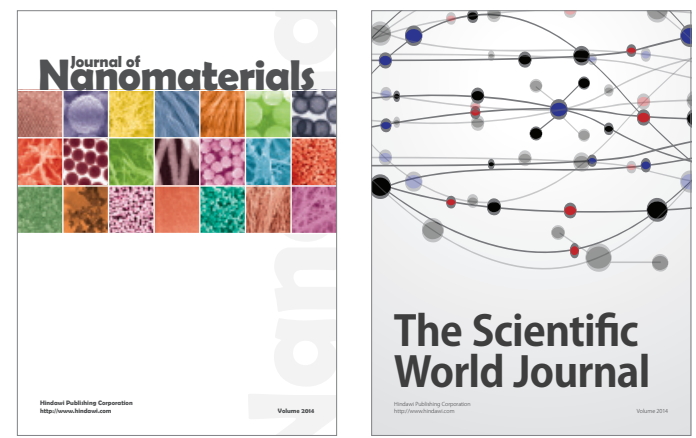

The Scientific World Journal
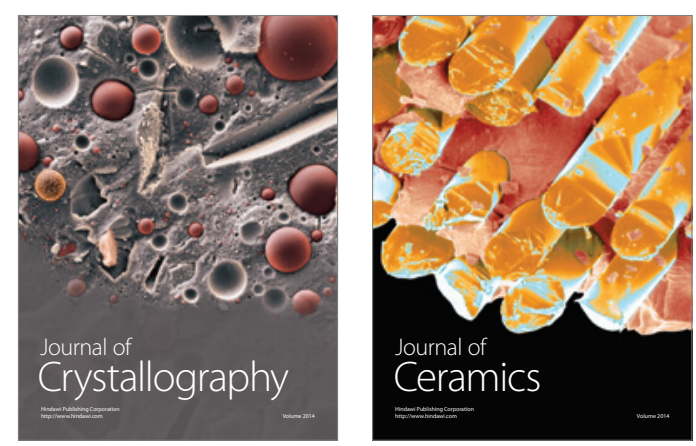
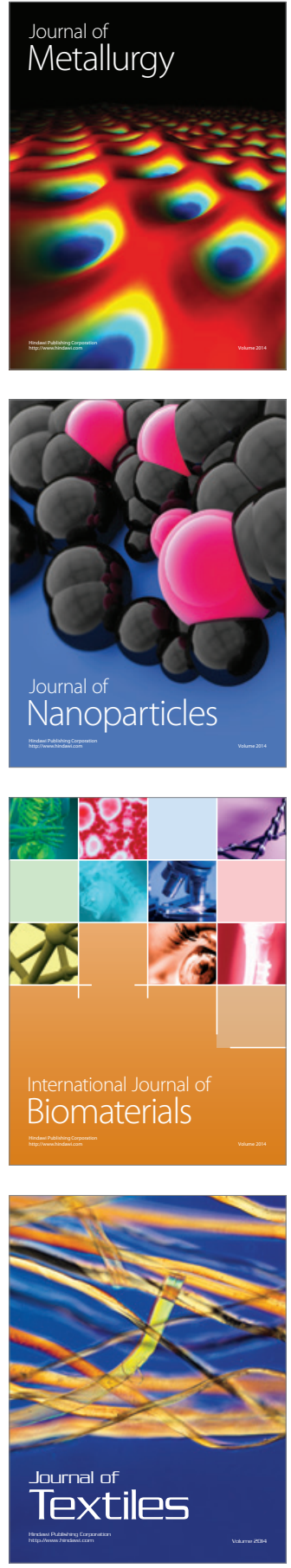